\title{
REFLECTION
}

\section{It's Time to Shine the Light on Direct-to-Consumer Advertising}

Tim K. Mackey, MAS, $P b D^{1-5}$

Bryan A. Liang, PbD, MD, JD $D^{1,4,5}$

${ }^{1}$ Global Health Policy Institute, San Diego, California

${ }^{2}$ Department of Anesthesiology, University of California San Diego School of Medicine, San Diego, California

${ }^{3}$ Division of Global Public Health, University of California San Diego School of Medicine, San Diego, California

${ }^{4}$ Joint Masters Program in Health Policy and Law, University of California San Diego School of Medicine, San Diego, California

${ }^{5}$ San Diego Center for Patient Safety, University of California San Diego School of Medicine, San Diego, California
Conflicts of interest: authors report none.

\section{CORRESPONDING AUTHOR}

Timothy Ken Mackey, MAS, PhD Global Health Policy Institute 8950 Villa La Jolla Drive, Suite \#A204 La Jolla, CA 92037 tmackey@ucsd.edu

\begin{abstract}
Pharmaceutical marketing is undergoing a transition as the business, delivery, and consumption of health care have increasingly become part of a growing digital landscape. Changes in pharmaceutical promotion also coincide with federal "sunshine" regulations newly implemented under the Affordable Care Act that require disclosure of certain marketing and industry payments to physicians. Collectively, these trends could lead to fundamental shifts in physician-directed and direct-to-consumer advertising (DTCA) that have yet to be adequately identified or explored. In response, we advocate for greater DTCA transparency, especially in the emerging digital forms of DTCA, to complement forthcoming sunshine transparency data. This will allow more robust study and understanding of changes in overall pharmaceutical marketing trends and their impact on health care consumption and behavior. This can also lead to more targeted state and federal policy interventions leveraging existing federal transparency regulations to ensure appropriate marketing, sales, and consumption of pharmaceutical products.
\end{abstract}

Ann Fam Med 2015;13:82-85. doi: 10.1370/afm.1711.

\section{BACKGROUND}

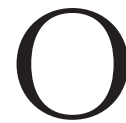
ver the past few decades, US pharmaceutical marketing has evolved in new and unexpected ways, as the business of health care has become part of a growing "eHealth" landscape. Increasingly, patients and other consumers, clinicians, and the industry have started to embrace emerging forms of digital technology (eg, the "health Internet," mobile health applications, self-tracking devices, and social media) that can influence health care information sourcing, consumption, and delivery. As an indication of this shift to "all things digital," the Pew Research Internet Project reports that $72 \%$ of surveyed US adults looked for health information online within the past year, $69 \%$ track at least 1 health indicator such as weight, exercise, symptoms, blood pressure, or sleeping patterns (with $21 \%$ of respondents using a form of technology to do so), and $52 \%$ of smartphone users use their devices to search for medical/health information. ${ }^{1}$

With consumers increasingly using information technology to deal with health issues, and with pharmaceutical manufacturers using directto-consumer advertising (DTCA) on the Internet, in social media, and through mobile applications (collectively "eDTCA"), ${ }^{3-6}$ traditionally dominant forms of pharmaceutical marketing, which include physician-directed promotion and advertising in traditional media (eg, television, radio, print, and outdoor advertisements) might also be changing.

\section{RISE, DECLINE, AND LACK OF TRANSPARENCY OF PHARMACEUTICAL MARKETING}

DTCA, a phenomenon legally permissible only in the United States and New Zealand among developed countries, ${ }^{2}$ experienced rapid growth 
in the United States when the US Food and Drug Administration (FDA) first liberalized its use in the 1980s and 1990s. ${ }^{7}$ An estimated 330\% rise in DTCA spending from 1996 to 2005 coincided with a wave of new FDA drug approvals, including approvals of "blockbuster" drugs such as Lipitor, Nexium, and Vioxx. ${ }^{8}$ This led to a proliferation of drug advertisements on TV and in print to which the vast majority of Americans were exposed, likely prompting patients to request a promoted drug from their physician. ${ }^{9,10}$ After hitting a peak of $\$ 5.89$ billion in 2006, DTCA began to decline, with spending estimated to be $\$ 4.37$ billion in 2010. This decrease has largely been attributed to dwindling drug pipelines, blockbuster patent expirations, and the recent global economic slowdown, ${ }^{11-13}$ although certain subcategories (eg, television) are experiencing sharper declines than others (eg, the Internet). ${ }^{11}$

Proponents emphasize DTCA's potential to educate consumers, while critics argue that DTCA leads to overemphasis on benefits vs risks, inappropriate prescribing, and increased national drug expenditures. ${ }^{8-10}$ Some have called for a complete ban on DTCA, while others have called for a temporary moratorium on new drug approvals, pointing out that many blockbuster drugs aggressively marketed through DTCA were later discovered to have adverse or harmful effects-some severe enough to result in their withdrawal, as in the case of Vioxx. ${ }^{8,10,14}$

Though DTCA has been the subject of debate, one inconvenient fact has made it difficult for researchers and policy makers to assess its economic and health impact: lack of transparency and public reporting of DTCA data. Though attempts have been made to quantify overall pharmaceutical promotion accurately, issues regarding its proprietary nature, the need to source information from third-party marketing firms and data analysis firms rather than directly from advertisers, and the lack of regulation requiring public reporting and transparency have all limited evidencebased assessment. ${ }^{15}$ This specifically includes DTCA expenditure data (notably for eDTCA), with information available almost exclusively from proprietary and fee-based marketing firms that differ in reported estimates. These firms generally conduct surveys and monitor promotion from samples of national media data sources for data collection.

\section{SHINING THE LIGHT ON PHYSICIAN- DIRECTED PROMOTION, BUT NOT DTCA?}

The "Transparency Reports and Reporting of Physician Ownership or Investment Interests" section of the US Affordable Care Act, commonly called "The
Sunshine Act," which has given rise to the Centers for Medicare \& Medicaid Services (CMS) Open Payments system, will in 2014 expose a large category of pharmaceutical marketing expenditures to public scrutiny for the first time. ${ }^{16}$ The law mandates that drug and device manufacturers now publicly report certain payments made to physicians and teaching hospitals (including entertainment, gifts, food, travel, consulting fees, honoraria, education or conference fees, and other forms of "transfers of value") annually, with monetary penalties for noncompliance. ${ }^{16}$ This policy change, largely a response to concerns over physicianindustry conflicts of interest, will provide detailed and validated data regarding important forms of national physician-directed promotion expenditures that will be public and freely available. ${ }^{16}$

Missing from this potentially groundbreaking legislation, however, are any requirements for transparency and reporting of DTCA expenditures by industry. Specifically, the regulations only cover certain forms of promotion directed to licensed physicians and teaching hospitals, not promotion directed to the consumer. Pharmaceutical DTCA is different from other forms of consumer marketing in that consumers do not directly purchase promoted pharmaceutical products as they do other consumer goods. Instead, pharmaceuticals require appropriate consultation and monitoring by healthcare professionals for use and dispensing hence, DTCA content must be appropriately understood and regulated to ensure that it facilitates appropriate interactions between patients and physicians that balance the risks and benefits of treatment. ${ }^{8}$

The Sunshine Act is primarily aimed at curtailing gifts and favors to individual physicians, so it may have limited impact on certain forms of physician detailing, specifically those detailing encounters that do not involve a transfer of value or are nonreportable (e.g. involve a transfer of value less than $\$ 10$, or $\$ 100$ in the aggregate for a calendar year). Nor does it address drug sampling, which can also lead to physician-industry marketing encounters. ${ }^{17}$ Further, the act will not prevent broader physician-directed marketing through medical journals, medical websites (eg, WebMD) and through advertising embedded into mobile apps such as Epocrates. ${ }^{18}$ Hence, it is likely that physician-directed pharmaceutical marketing will simply shift to more subtle forms of promotion that are difficult to detect, not reportable, or emerging in new and largely unregulated media such as the Internet.

Changes in physician-directed promotion as a result of transparency requirements could also overlap with changes in DTCA strategies now focusing on meeting consumers where they predominantly search for and consume health information: online. ${ }^{1}$ Innova- 


\section{Table 1: Proposed Public DTCA Disclosure Categories}

\begin{tabular}{ll}
\hline DTCA Data Category & Description \\
\hline Expenditure amount & $\begin{array}{c}\text { Monetary value (\$USD) for promotion for each marketing } \\
\text { medium utilized } \\
\text { Product claims ad, reminder ad, help-seeking ad }\end{array}$ \\
$\begin{array}{l}\text { Category of DTCA } \\
\text { Marketing medium }\end{array}$ & $\begin{array}{l}\text { Thescription drug coupon, etc. } \\
\text { Language(s) utilized in DTCA }\end{array}$ \\
$\begin{array}{l}\text { Location } \\
\text { Time }\end{array}$ & $\begin{array}{l}\text { Length (in days) of DTCA promotional campaign } \\
\text { Product class }\end{array}$ \\
$\begin{array}{l}\text { Therapeutic category } \\
\text { Pisease associated }\end{array}$ & Therapeutic category of DTCA product \\
Name of product & Disease information associated with DTCA \\
\end{tabular}

sionals, and policy makers should collectively advocate for greater transparency of DTCA to better understand its influence on pharmaceutical and health care utilization and consumer behavior. Physicians play an important role in advocating for this change because their clinical practice and relationship with patients could be the most adversely affected and because of the heightened need for physicians to guide patients concerning DTCA claims. Hence, we believe this is an opportune time to leverage the Sunshine Act to finally shed light on DTCA. tive eDTCA tactics are being used more frequentlytactics such as offering electronic prescription drug coupons and marketing to consumers through patientengagement Web portals. ${ }^{6,19}$ So far, eDTCA is not regulated well by the FDA, which released draft guidance on the use of "interactive promotional media" by industry only recently, in early 2014, and the draft is subject to further comments and finalization. ${ }^{20,21}$ The nature of the Internet means that eDTCA has the ability to cross country borders and spread globally, despite its prohibition in almost all countries. ${ }^{4}$ Hence, increased use of eDTCA could have global public health consequences, especially if not well identified and regulated.

Without reliable and accessible data on DTCA and eDTCA promotional expenditure, it will be difficult to compare changing trends in physician-directed promotion with trends in DTCA spending. To get a clearer picture of the overall impact of pharmaceutical promotion in the changing digital health landscape, stakeholders should demand increased transparency of DTCA. We propose some initial DTCA disclosure requirements to meet these goals (Table 1). These data fields could be reported in a public online database similar to the CMS Open Payments system using a similar infrastructure to lower implementation costs.

Policy reform to mandate DTCA transparency could be pursued at the state and federal level. As has already happened in states such as Minnesota, Vermont, Maine, and West Virginia, state legislators eager to understand the health and economic impact of DTCA could enact state legislation requiring disclosure of DTCA expenditures targeted at their residents (a requirement not preempted by the Sunshine Act). 16,22 Another option is to seek clarification on whether the statutory language of the Sunshine Act permits CMS to add DTCA reporting as a new reportable category under existing regulations. ${ }^{16}$

Consumers, public health and health care profes-
To read or post commentaries in response to this article, see it online at http://www.annfammed.org/content/13/1/82.

Key words: direct-to-consumer advertising; Sunshine Act; physician payments; conflicts of interest; health marketing and promotion; health policy; eHealth

Submitted June 4, 2014; submitted, revised, July 25, 2014; accepted September 1, 2014.

\section{REFERENCES}

1. Pew Research Internet Project. Health Fact Sheet. http://www.pew internet.org/fact-sheets/health-fact-sheet/. Published 2013. Accessed Apr 29, 2014.

2. Mackey TK, Liang BA. Pharmaceutical digital marketing and governance: illicit actors and challenges to global patient safety and public health. Global Health. 2013;9(1):45.

3. Liang BA, Mackey TK. Prevalence and Global Health implications of social media in direct-to-consumer drug advertising. J Med Internet Res. 2011;13(3):e64.

4. Liang BA, Mackey T. Direct-to-consumer advertising with interactive internet media: global regulation and public health issues. JAMA. 2011;305(8):824-825.

5. IMS Institute for Healthcare Informatics. Engaging Patients Through Social Media. http://www.imshealth.com/deployedfiles/imshealth/ Global/Content/Corporate/IMS\%20Health\%2OInstitute/Reports/ Secure/IIHI_Social_Media_Report_2014.pdf. Published Jan 2014.

6. Collier R. Patient engagement or social media marketing? CMAJ. 2014;186(8):E237-E238.

7. Palumbo FB, Mullins CD. The development of direct-to-consumer prescription drug advertising regulation. Food Drug Law J. 2002;57(3):423-443.

8. Liang BA, Mackey T. Reforming direct-to-consumer advertising. Nat Biotechnol. 2011;29(5):397-400.

9. Donohue JM, Cevasco M, Rosenthal MB. A decade of direct-toconsumer advertising of prescription drugs. N Engl J Med. 2007; 357(7):673-681.

10. Kravitz RL, Bell RA. Direct-to-consumer advertising of prescription drugs: balancing benefits and risks, and a way forward. Clin Pharmacol Ther. 2007;82(4):360-362.

11. Kornfield R, Donohue J, Berndt ER, Alexander GC. Promotion of Prescription Drugs to Consumers and Providers, 2001-2010. PLoS One. 2013;8(3):e55504. http://www.plosone.org/article/ info\%3Adoi\%2F10.1371\%2Fjournal.pone.0055504. Published Mar 4, 2013. 
12. Harrison C. Patent watch: the patent cliff steepens. Nat Rev Drug Discov. 2011;10(1):12-13.

13. Calabrese M, Migliorini M. 2010 Direct-To-Consumer Industry Check-up. http://crm.cegedim.com/Docs_Whitepaper/Marketing/ DTC_Survey_Whitepaper_June_2010.pdf. Published Jun 2010. Accessed Sep 23, 2013.

14. Waxman HA. The lessons of Vioxx-drug safety and sales. N Engl J Med. 2005;352(25):2576-2578.

15. Gagnon M-A, Lexchin J. The cost of pushing pills: a new estimate of pharmaceutical promotion expenditures in the United States. PLoS Med. 2008;5(1):e1. http://www.plosmedicine.org/article/ info\%3Adoi\%2F10.1371\%2Fjournal.pmed.0050001. Published Jan 3, 2008.

16. Mackey TK, Liang BA. Physician payment disclosure under health care reform: will the sun shine? J Am Board Fam Med. 2013;26(3):327-331.

17. Fugh-Berman A, Ahari S. Following the Script: How Drug Reps Make Friends and Influence Doctors. PLOS Med. 2007;4(4):e150. http:// www.plosmedicine.org/article/info\%3Adoi\%2F10.1371\%2Fjournal pmed.0040150. Published Apr 24, 2007.
18. Wilson D. Drug App Comes Free, Ads Included. New York Times. July 29, 2011:B1. http://www.nytimes.com/2011/07/29/business/ the-epocrates-app-provides-drug-information-and-drug-ads. html?pagewanted=allE_r=0. Accessed Jul 24, 2014.

19. Mackey TK, Yagi N, Liang BA. Prescription drug coupons: evolution and need for regulation in direct-to-consumer advertising. Res Social Adm Pharm. 2014;10(3):588-594.

20. Wang B, Kesselheim AS. The role of direct-to-consumer pharmaceutical advertising in patient consumerism. Virtual Mentor. 2013;15(11): 960-965.

21. Osborn J. FDA Draft Guidance Takes the "Social" Out Of Social Meda. Forbes. http://www.forbes.com/sites/johnosborn/2014/05/13/ fda-draft-guidance-takes-the-social-out-of-social-medial. Published May 3, 2014. Accessed Jun 2, 2014.

22. Mackey TK, Liang BA. Transparency in Physician-Industry Relationships: State and Federal Efforts. Pathol Case Rev. 2012;17(4):144-147.

\section{Get the Annals of Family Medicine by E-mail}

Make sure you see every new issue
while it's fresh; have the table of
contents sent to you by e-mail for
easy access to articles of interest.

Don't miss important research.

Request the e-mail table of contents at

http://www2.highroadsolution.com/

aafp_annals_preference_center/search.aspx

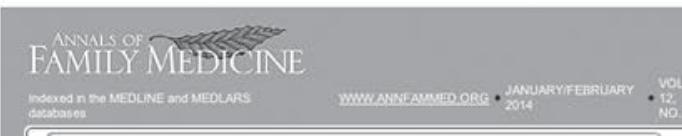

Impact Factor Announcement

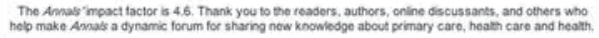

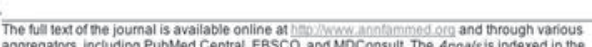
aggregations, including PubMed Central, EBSCO, and MOConsult The Amnals is indexed in the PSYCINFO, EMBASE, and CINHAL databases.

EDITORIALS

Kutt C. Stange

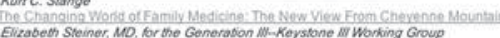

Unressives internenestational is

Kurt C. Stange: John $\alpha$ Frey III

Kato Rowatand

ORIGINAL RESEARCH

Prectice Facilitation to Improve Diabetes Care in Primary Care: A Report From the EPIC

W. Perry Dickinson: L. Mintam Dickinson: Paul A. Mutting Caroline B. Emsermann: Brandon Tutt: Benjamin F. Crabtree, Lawrence Fisher, Magvie Harbrecht; Alyson Gottsman; David R West Traditional continuous quality improvement inteverlions are elloctive at improving diabetos 作 ars E. Peterson Bremng E. Blackoum:

Analysis of the American Board of Family Medicine Maintenance of Certification diabetes quality improvement data from 8,000 family physicians shows improvement in patient care from this process.

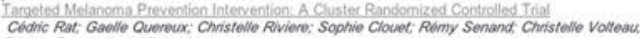

Brigitte Dreno: Jean-Micher Nguyen
A targeted screening and education intervention is more effective than conventional information for improving melanoma prevention behavior and skin self-examination in high-risk family medicine pation

Ac

Mohammed Mustafa: Fiona Wood, Chistopher C. Butler, Gynn Ehyn

When treating upper respiratory tract infections, family physicians prefer to elicit patients 